\title{
Weight Stigma and Disease and Disability Concepts of Obesity: A Survey of the German Population
}

\author{
Anja Hilbert $^{\mathrm{a}}$ Markus Zenger ${ }^{\mathrm{a}, \mathrm{b}}$ Claudia Luck-Sikorski ${ }^{\mathrm{c}}$ Elmar Brähler ${ }^{\mathrm{a}, \mathrm{d}}$ \\ aBehavioral Medicine Research Unit, Integrated Research and Treatment Center AdiposityDiseases, Department \\ of Psychosomatic Medicine and Psychotherapy, University of Leipzig Medical Center, Leipzig, Germany; ${ }^{\text {b Faculty }}$ \\ of Applied Human Studies, University of Applied Sciences Magdeburg and Stendal, Stendal, Germany; ${ }^{\circ}$ Research \\ Group COPE, SRH University of Applied Health Sciences, Gera, Germany; ${ }^{d}$ Department of Psychosomatic Medicine \\ and Psychotherapy, University Medical Center of the Johannes Gutenberg University of Mainz, Mainz, Germany
}

\section{Keywords \\ Weight stigma - Weight bias · Disease concept · Disability · Population-based survey}

\begin{abstract}
Introduction: Recent years have witnessed a medicalization of obesity, promoting a classification as a disease or disability in order to reduce or protect against weight stigma and discrimination. This study sought to investigate the public understanding of the disability and disease concepts in obesity, their acceptance, and association with weight stigma. Methods: In a representative German population sample $(n=2,524)$, public views of obesity as a disease or disability were assessed via a self-report questionnaire. For the assessment of weight stigma, the Weight Control/Blame subscale from the Antifat Attitudes Test was used. Results: A significantly greater acceptance of the disease than the disability concept was found ( 37.1 vs. $15.4 \%$ ). Both disease and disability were mainly viewed as physical conditions, although onethird also viewed obesity as a mental disease. While agreement with the disease concept - especially of physical and genetic disease - significantly predicted lower weight stigma; agreement with the disability concept - especially of
\end{abstract}

mental or intellectual disability - predicted higher weight stigma. Conclusions: These results suggest a careful use of the disease and disability terms and precise definitions. The disability concept in particular carries notions that are publicly devalued.

(c) 2021 The Author(s)

Published by S. Karger AG, Basel

\section{Introduction}

Individuals with obesity, a prevalent health condition defined by a body mass index (BMI) of $\geq 30 \mathrm{~kg} / \mathrm{m}^{2}$ [1], pervasively encounter weight stigma, including negative stereotypes, prejudice, and discrimination, in many domains of life, with detrimental effects on their health and well-being [2]. Recent years have witnessed a medicalization of obesity, promoting a classification of obesity as a disease or disability that is aimed at reducing or protecting against weight stigma and granting equal treatment for this chronic condition [3]. As this medicalization is likely to influence public views of obesity, the understanding of obesity as a disease or disability and the associations with weight stigma warrant further research.

Correspondence to: 
Although obesity has been recognized as a disease by the World Health Organization since 1949, it was only in 2013 announced and officially classified as a disease by the American Medical Association [4], which other medical societies followed [3, 5-7]. Acknowledging the absence of a single authoritative definition of disease in general $[8]$ and obesity in particular $[6,9,10]$, the rationale for classifying obesity as chronic medical disease was fueled by the requirement to advance evidence-based prevention and treatment in order to improve health outcomes for this condition. In contrast to the diverse disease definitions typically focusing on pathogenic processes, symptomatic manifestations, and functional alterations in body parts, organs, or systems with negative impact on health [4], disability, another medical concept that has been applied to obesity, is instead concerned with longstanding and severe functional impairment hindering daily living. By definition, disability, an umbrella term, refers to long-term physical, mental, intellectual, or sensory impairments that limit activity and restrict participation in daily life [11]. Although diseases - especially if chronic and/or severe - can lead to impairment that may qualify for disability according to this definition, the presence of a disease is not a requirement for disability [12]. While the public may not be fully aware of the scientific definitions of disease and disability, the medicalization associated with the application of these 2 concepts to obesity may nevertheless impact public views of obesity with potential relevance for weight stigma.

Specifically, regarding the classification of obesity as a disease, the medicalization of this condition that is commonly viewed as a risk factor of noncommunicable diseases [1] has been critically discussed for various reasons, including its potential to increase weight stigma because of an "abnormal" categorization [6, 7]. However, population surveys showed that the disease classification that references obesity as a physical disease, was generally well received, and was related to lower weight stigma $[13,14]$. In addition, it remains unclear how other disease concepts, for example, of genetic disease [15] or mental disease [16], are publicly applied to this condition and which associations they show with weight stigma. In parallel with findings on attributions of obesity to controllable versus uncontrollable internal causes [7] within the framework of the prominent attribution theory [17], the mental disease concept may be associated with greater weight stigma, because the attribution of obesity to psychological factors involving personal control or responsibility may be emphasized, provoking blame and negative reactions. In addition, the mental disease concept may relate to the common stereotype of people with obesity having emotional problems, whereby the mental disease concept may have a compounding effect on weight stigma [18]. In contrast to the mental disease concept, the opposite may hold true for the genetic disease concept, whereby - similarly to the physical disease concept - the attribution to uncontrollable internal causes such as a genetic predisposition may de-emphasize the personal responsibility for obesity and reduce blame and negative reactions.

Regarding disability, individuals with obesity, especially at higher severity levels, suffer from a range of impairments in mobility and self-care [19], which may account for disability according to the above described definition and build a case for legal measures including those to reduce or protect against weight stigma [20]. For example, if long-term physical, mental, or intellectual impairments were present to limit participation in life, or if severe obesity was considered an impairment, this would make it subject to protection through antidiscrimination laws. Regarding public views, while population surveys showed only moderate support for the recognition of obesity as a physical disability in antidiscrimination jurisdiction [21-23], it remains unknown whether obesity is regarded as a disability; whether the focus would be on physical, mental, or intellectual disability; and whether this disability designation is associated with weight stigma. Further clarification is warranted, as disability generally co-occurs with stigmatization, stereotyping individuals with disabilities as incompetent, incapacitated, dependent, and persistently different [24].

The goal of this study was to investigate public views on obesity as a disease or disability and their associations with weight stigma. We hypothesized a greater agreement with the disease concept than with the less prominent disability concept, with prevailing focus on physical aspects than on other aspects, while examining variations by age, sex, and BMI. We further expected the disease concept, especially the focus on physical or genetic aspects, to predict lower weight stigma, and the disability concept to predict higher weight stigma, as disability is associated with higher severity levels of obesity and long-standing impairment, and is highly stigmatized in itself.

\section{Methods}

Participants

A German population sample was drawn in March 2016 with assistance by an independent institute specializing in market, opinion, and social research (USUMA, Berlin, Germany). A three- 
stage random sampling procedure was used to select: sample point regions based on representative data; target households within regions using a random route procedure; and target persons within households according to a Kish selection grid.

Following this procedure, 4,830 noninstitutionalized civilians $\geq 14$ years were randomly selected, and 2,544 individuals participated in the survey, corresponding to a response rate of $52.7 \%$ (households: 693 not reached and 721 refused; target persons: 127 not reached, 14 incapacitated, and 731 refused). Because of missing data, $20(0.4 \%)$ of participants were excluded, leaving a final sample of $n=2,524$ individuals.

Upon visit by a research assistant, all participants were informed about the study procedures in a verbal and written format and signed an informed consent prior to assessment. For minor participants, informed consent was additionally obtained from 1 parent. The study, performed in accordance with the Declaration of Helsinki, was approved by the Ethics Committee of the University of Leipzig (no. 452-15-21122015).

The total study sample consisted of 1,145 men (45.4\%) and 1,379 women $(54.6 \%)$ with a mean age of 48.84 years $(S D=18.18$; 14-30 years: $19.0 \%, 31-60$ years: $52.7 \%$, and 61 years $+: 28.3 \%$ ) and a mean BMI of $25.87 \mathrm{~kg} / \mathrm{m}^{2}$ (SD = 4.76), calculated from self-reported height and weight. Regarding weight status, $47.3 \%$ were classified as normal weight or underweight $\left(\right.$ BMI $<25.0 \mathrm{~kg} / \mathrm{m}^{2}$; $1.1 \%$ with underweight, BMI $<18.5 \mathrm{~kg} / \mathrm{m}^{2}$ ), $38.7 \%$ were classified as overweight (BMI $25.0-29.9 \mathrm{~kg} / \mathrm{m}^{2}$ ), and $14.0 \%$ were classified as obese [1].

\section{Measures}

Public views of obesity as a disease or disability were assessed by a questionnaire. Because of a lack of validated assessments, obesity as a disease or disability was operationalized with 3 items each, designed by the first author, and checked for content and comprehensibility by the second and last authors. In order to cover the main aspects of these concepts, the items focused on physical, mental, and genetic disease and on physical, mental, and intellectual disability and were given as statements (e.g., "Obesity is a physical disease;" "Obesity is an intellectual disability"). In order to assess agreement with the items, they were presented with a 5 -point Likert scale (from 1 = disagree completely to $5=$ agree completely). For data analysis, single items and mean composite scores of public views of obesity as a disease or disability were examined. A principal components analysis with orthogonal VARIMAX rotation supported a two-factor solution, accounting for $62.8 \%$ of the variance, with the first factor containing 3 disability items (34.3\% variance explanation) and the second factor containing 3 disease items (28.5\%). Internal consistency was Cronbach's $\alpha=0.59$ for the disease concept and $\alpha=0.72$ for the disability concept. Both concepts were moderately correlated $(r=0.48, p<$ $0.001)$. For illustrative purposes, response scores $\geq 4$ were formed to indicate definitive agreement.

For the assessment of weight stigma, the validated 9-item subscale "Weight Control/Blame" from the Antifat Attitudes Test was used (e.g., "Fat people have no willpower;" from 1 = strongly disagree to $5=$ strongly agree) [25]. Internal consistency was Cronbach's $\alpha=0.81$ based on this study's sample.

\section{Data Analytic Plan}

Public views of obesity as a disease or disability (mean) were compared in a general linear model (GLM) analysis with repeated

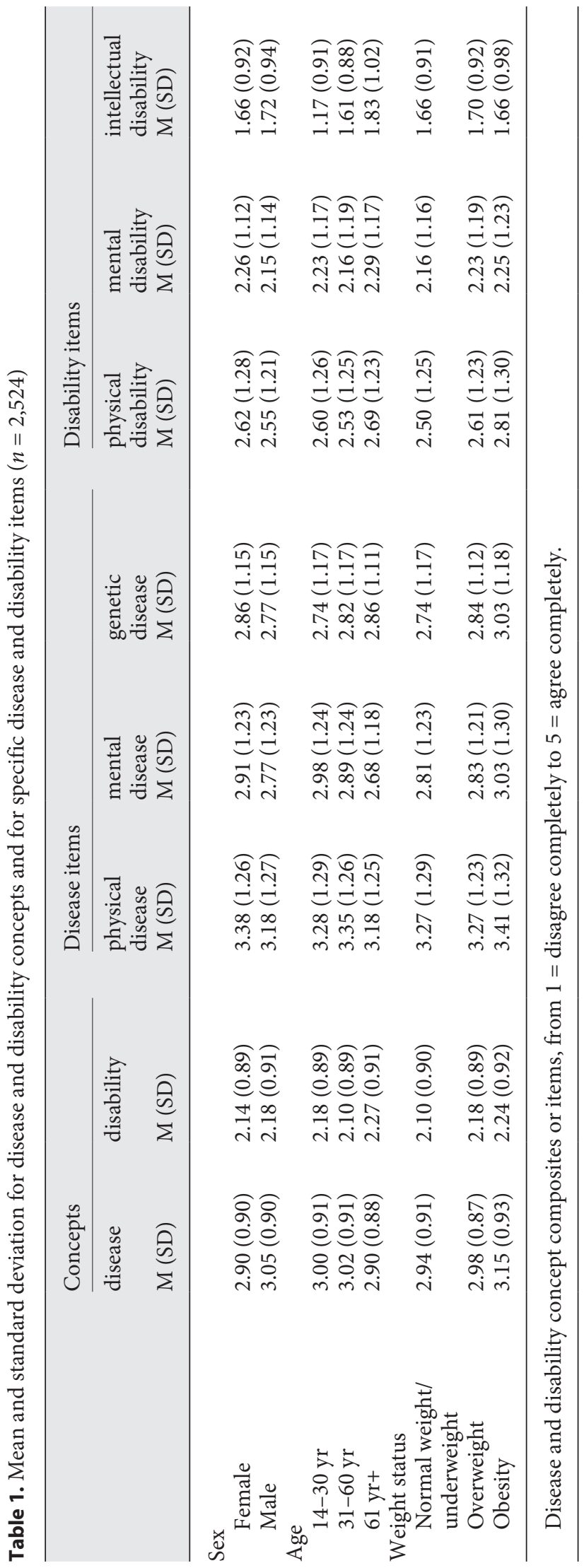

Obes Facts 2021;14:463-470

DOI: $10.1159 / 000516494$ 


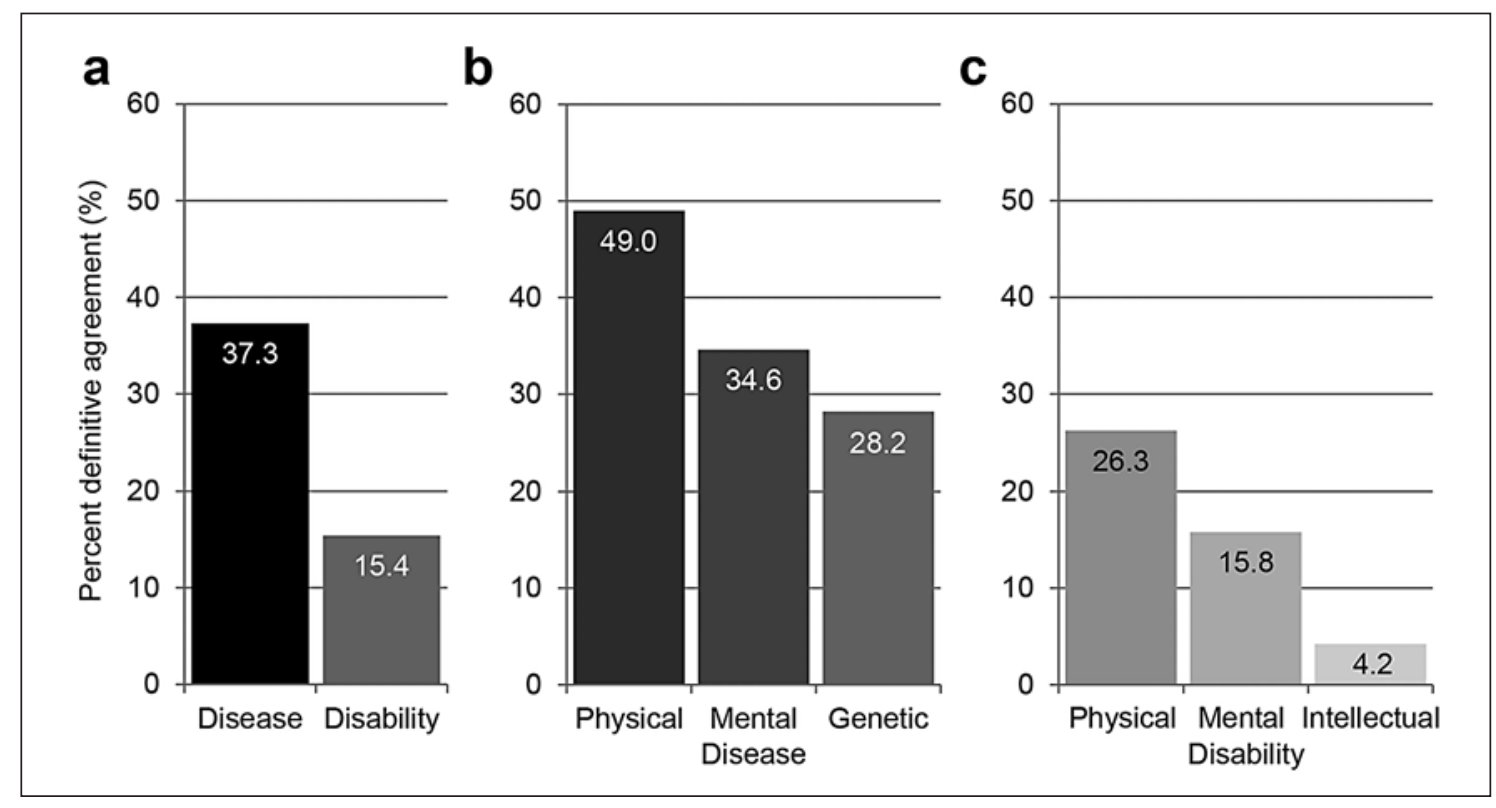

Fig. 1. Public views of obesity as a disease and disability: definitive agreement. Agreement with disease and disability concept composites (a), disease items (b), and disability items (c). Displayed are the frequencies of response scores $\geq 4$, indicating definitive agreement with obesity as a disease or disability.

measures of the Concept (disease, disability; within factor) $\times$ Sex (male, female) $\times$ Age (14-30 years, 31-60 years, 61 years +$) \times$ Weight status (normal weight/underweight, overweight, obesity; between factors). Main effects and interactions between the concept and sociodemographic variables were reported, using withinsubject contrasts or Tukey tests for post hoc analyses, respectively. For ensuring readability, only significant post hoc tests were displayed. Hierarchical linear regression analysis served to examine the predictive value of the disease or disability concept (block 2) for weight stigma, controlled by sociodemographic variables (block 1; sex [male, female], age [years], and BMI $\left[\mathrm{kg} / \mathrm{m}^{2}\right]$ ). In an additional regression analysis, interactions among the disease and disability concepts and sociodemographic variables with significance in the GLM analysis were entered in block 3. Predictor variables were mean centered. Similar models were used to compare the specific disease and disability items. Data analysis was performed using IBM SPSS Statistics for Windows (version 26.0), and was based on unweighted data. A 2-tailed $\alpha$ of 0.05 was applied to statistical tests.

\section{Results}

In the GLM analysis, agreement with the disease concept was significantly higher than that with the disability concept, $F[1,2,272]=860.23, p<0.001$, partial $\eta_{p}{ }^{2}=0.275$ (Table 1; see Fig. 1 for definitive agreement). The agreement with the disease versus disability concept showed interactions with sex, $F[1,2,272]=4.74, p=0.030, \eta_{p}{ }^{2}=$ 0.002 , and age, $F[2,2,272]=21.17, p<0.001, \eta_{p}{ }^{2}=0.018$, but not with weight status, $F[2,2,272]=0.46, p=0.633$, $\eta_{p}{ }^{2}=0.000$. In post hoc tests, women endorsed the disease concept, $F[1,2,309]=14.72, p<0.001, \eta_{p}{ }^{2}=0.850$, but not the disability concept, more than men. Middle-aged participants agreed more with the disease concept than older participants $(31-60$ years $>61$ years + ; mean difference $=$ $0.12, \mathrm{SE}=0.04, p=0.018,95 \%$ CI 0.02-0.22), while the disability concept was endorsed more by older participants (61 years $+>31-60$ years; mean difference $=0.17$, $\mathrm{SE}=0.04, p<0.001,95 \%$ CI 0.06-0.272). Higher order interactions between the disease versus disability concept and sociodemographic variables were nonsignificant, $F[2-4,2,272]=0.23-1.27, p=0.278-0.794, \eta_{p}{ }^{2}=0.000-$ 0.002 . Overall, agreement with both the disease and the disability concept was greater in women than men, $F[1,2,272]=9.74, p=0.002, \eta_{p}^{2}=0.004$; in younger than older individuals, $F[2,2,272]=3.86, p=0.021, \eta_{p}{ }^{2}=0.003$; and in individuals with obesity versus those with overweight and normal weight/underweight, $F[2,2,272]=$ 9.29, $p<0.001, \eta_{p}{ }^{2}=0.008$ (obesity $>$ overweight, mean difference $=0.12, \mathrm{SE}=0.05, p=0.034,95 \%$ CI $0.01-0.24$; obesity $>$ normal weight/underweight, mean difference $=$ $0.18, \mathrm{SE}=0.05, p=0.001,95 \%$ CI 0.07-0.30).

Considering the specific disease items, viewing obesity as a physical disease yielded a greater agreement than viewing obesity as a genetic disease, $F[2,2,309]=65.67, p<$ $0.001, \eta_{p}^{2}=0.028$, and post hoc tests, $F[1,2,309]=106.51$, 
Table 2. Hierarchical linear regression analysis predicting weight stigma from (a) disease and disability concepts, (b) from disease and disability concepts and interactions with sociodemographic variables, and from (c) specific disease and disability items $(n=2,524)$

\begin{tabular}{|c|c|c|c|c|c|c|}
\hline & $B$ & SE & $\beta$ & $T$ & $p$ value & $95 \% \mathrm{CI}$ \\
\hline \multicolumn{7}{|c|}{ a Disease and disability concept } \\
\hline \multicolumn{7}{|l|}{ Block 1} \\
\hline Constant & 3.264 & 0.047 & & & & \\
\hline Sex, female & -0.168 & 0.029 & -0.114 & -5.747 & $<0.001$ & $-0.226,-0.111$ \\
\hline Age, yr & -0.001 & 0.001 & -0.021 & -1.027 & 0.304 & $-0.002,0.001$ \\
\hline BMI, $\mathrm{kg} / \mathrm{m}^{2}$ & -0.036 & 0.003 & -0.232 & -11.514 & $<0.001$ & $-0.042,-0.029$ \\
\hline \multicolumn{7}{|l|}{ Block 2} \\
\hline Disease concept & -0.175 & 0.019 & -0.214 & -9.433 & $<0.001$ & $-0.211,-0.138$ \\
\hline Disability concept & 0.128 & 0.018 & 0.157 & 6.951 & $<0.001$ & $0.092,0.164$ \\
\hline \multicolumn{7}{|c|}{ b Disease and disability concepts with interactions } \\
\hline \multicolumn{7}{|l|}{ Block 1} \\
\hline Constant & 3.266 & 0.047 & & & & \\
\hline Sex, female & -0.171 & 0.029 & -0.116 & -5.862 & $<0.001$ & $-0.228,-0.114$ \\
\hline Age, yr & -0.001 & 0.001 & -0.022 & -1.077 & 0.282 & $-0.002,0.001$ \\
\hline $\mathrm{BMI}, \mathrm{kg} / \mathrm{m}^{2}$ & -0.035 & 0.003 & -0.230 & -11.423 & $<0.001$ & $-0.041,-0.029$ \\
\hline \multicolumn{7}{|l|}{ Block 2} \\
\hline Disease concept & -0.219 & 0.053 & -0.268 & -4.109 & $<0.001$ & $-0.323,-0.114$ \\
\hline Disability concept & 0.126 & 0.018 & 0.154 & 6.860 & $<0.001$ & $0.090,0.161$ \\
\hline \multicolumn{7}{|l|}{ Block 3} \\
\hline Disease concept $\times$ Sex & 0.033 & 0.032 & 0.065 & 1.015 & 0.310 & $-0.031,0.096$ \\
\hline Disease concept $\times$ Age & 0.003 & 0.001 & 0.064 & 2.810 & 0.005 & $0.001,0.005$ \\
\hline Disability concept $\times$ Age & 0.002 & 0.001 & 0.055 & 2.421 & 0.016 & $0.000,0.004$ \\
\hline \multicolumn{7}{|l|}{ c Disease and disability items } \\
\hline \multicolumn{7}{|l|}{ Block 1} \\
\hline Constant & 4.450 & 0.106 & & & & \\
\hline Sex, female & -0.168 & 0.029 & -0.114 & -5.744 & $<0.001$ & $-0.225,-0.111$ \\
\hline Age, yr & 0.000 & 0.001 & -0.009 & -0.467 & 0.641 & $-0.002,0.001$ \\
\hline $\mathrm{BMI}, \mathrm{kg} / \mathrm{m}^{2}$ & -0.035 & 0.003 & -0.229 & -11.409 & $<0.001$ & $-0.041,-0.029$ \\
\hline \multicolumn{7}{|l|}{ Block 2} \\
\hline Physical disease & -0.059 & 0.013 & -0.101 & -4.710 & $<0.001$ & $-0.083,-0.034$ \\
\hline Mental disease & 0.004 & 0.014 & 0.006 & 0.254 & 0.800 & $-0.024,0.032$ \\
\hline Genetic disease & -0.115 & 0.014 & -0.181 & -8.024 & $<0.001$ & $-0.144,-0.087$ \\
\hline Physical disability & 0.020 & 0.014 & 0.034 & 1.403 & 0.161 & $-0.008,0.048$ \\
\hline Mental disability & 0.041 & 0.017 & 0.066 & 2.437 & 0.015 & $0.008,0.074$ \\
\hline Intellectual disability & 0.063 & 0.019 & 0.079 & 3.303 & 0.001 & $0.026,0.100$ \\
\hline \multicolumn{7}{|c|}{ 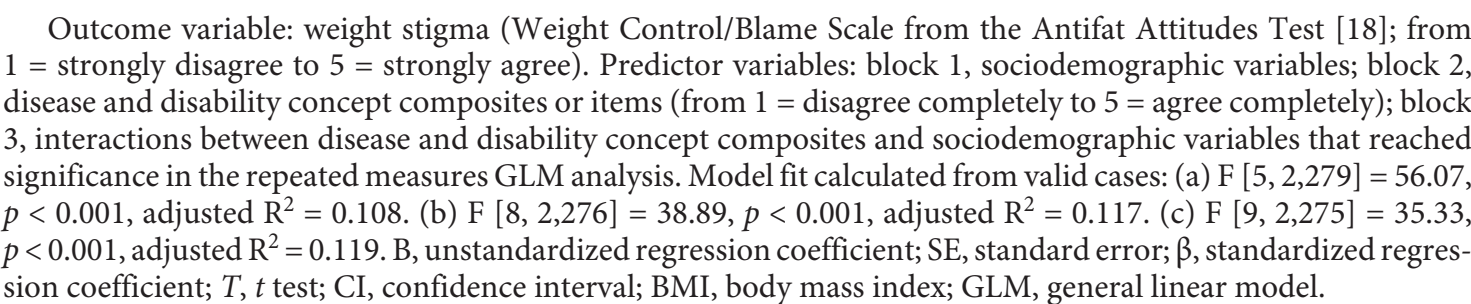 } \\
\hline
\end{tabular}


$p<0.001, \eta_{p}^{2}=0.044$ (Table 1; see Fig. 1 for definitive agreement). Similarly, agreement varied among the specific disability items, $F[2,2,296]=407.81, p<0.001, \eta_{p}{ }^{2}=$ 0.151 . Post hoc tests showed that agreement with obesity as a physical disability was greater than that with obesity as a mental disability, $F[1,2,296]=141.88, p<0.001, \eta_{p}{ }^{2}=$ 0.058 , and both were endorsed more often than obesity as an intellectual disability, $F[1,2,296]=692.51$ or 345.04 , both $p<0.001, \eta_{p}^{2}=0.232$ or 0.131 , respectively.

In the hierarchical linear regression analysis, agreement with the disease concept significantly negatively predicted weight stigma, while agreement with the disability concept positively predicted weight stigma (Table 2). Additional inclusion of interactions among disease and disability concepts and sociodemographic variables that reached significance in the repeated measures GLM analysis did not modify the results, and added only marginally to the prediction; interactions among age and the disease and disability concept positively predicted weight stigma. Among the disease items, agreement with obesity as a physical and genetic disease predicted lower weight stigma, while agreement with obesity as a mental disease was unrelated with weight stigma. In contrast, agreement with obesity as a mental or intellectual disability, but not with obesity as a physical disability, predicted greater weight stigma.

\section{Discussion}

This population-based survey uniquely investigated the public understanding and acceptance of the disability and disease concepts in obesity, and their association with weight stigma. The results showed that the disease concept yielded only moderate acceptance, consistent with previous research $[13,14]$, but expectedly more than the disability concept (definitive agreement: 37.1 vs. $15.4 \%$; Fig. 1). As hypothesized, among both concepts, obesity was mainly viewed as a physical disease or disability, although one-third also viewed obesity as a mental disease - in fact, weight stigma often includes attributions of mental disturbance [18].

Importantly, viewing obesity as a disease or disability showed inverse associations with weight stigma as hypothesized: while agreement with the disease concept significantly predicted lower weight stigma, agreement with the disability concept predicted higher weight stigma. When interactions with sociodemographic variables were additionally entered into the regression, the prediction was only marginally improved; plausibly, interactions between age, and the disease and disability concept (i.e., the product between age and agreement with the disease or disability concept) were predictive of greater weight stigma. Notably, specific notions drove the inverse associations between the disease versus disability concept and weight stigma, with views of obesity as a physical or genetic disease accounting for lower weight stigma. This is consistent with the literature $[13,14]$ and the predictions of attribution theory [17], according to which the attribution to uncontrollable internal causes decreases the personal responsibility for obesity and weight stigma. However, agreement with obesity as a mental disease was unrelated to weight stigma, which contrasts to evidence connecting behavioral attributions of obesity with higher weight stigma [13]; it is possible that in obesity, mental illness labeling emphasizes personal control and responsibility less than the reference to behavioral factors, as was found for the food addiction explanation model [26]. As opposed to the negative associations of views of obesity as a physical or genetic disease with lower weight stigma, views of obesity as a mental or intellectual disability accounted for higher weight stigma; the stigma of these disabilities seems to be especially harsh including, for example, stereotypes of incompetence, dependency, or differentness [24], whereas the view of obesity as a physical disability was unrelated with weight stigma.

Strengths of this study include the large sample drawn to be representative of the German population regarding age and sex [27]. The response rate of $52.7 \%$ is comparable to those commonly documented in general population research [28]. Most notably, the self-report assessment of anthropometrics led to an underreporting [29] and thus an underestimation of obesity ( 14.0 vs. $23.6 \%$ ) [30]. A further limitation, as assessments of public views of obesity as a disease and disability and their specific notions were unavailable, items were specifically designed for the purpose of this survey. Content validity was ensured through direct operationalization of the targeted content; factorial validity was demonstrated; and internal consistency was documented for the disability concept, but was poor for the disease concept, indicating heterogeneity of the disease items. For assessment of weight stigma, the psychometrically well-established Weight Control/Blame subscale from the Antifat Attitudes Test was used [25]. Finally, of note in the context of the open science initiative, this is a nonpreregistered report.

Regarding research implications, because of a notable lack of evidence on disease and disability concepts in relation to weight stigma, the nature of these associations warrants further clarification specifying underlying cognitions and emotions, including attributions. Beyond stigmatizing 
attitudes as assessed in this study, associations with other measures of weight stigma (e.g., behavioral measures on social distancing) as well as with self-stigma as an important correlate and predictor of psychopathology [31] are desirable. Because weight stigma may be potentiated by disease and/or disability stigmata [18], combined effects of layered stigma should systematically be investigated. Of note, because of the cross-sectional nature of our study, causality cannot be inferred and requires experimental research on the (de-)stigmatizing potential of disease or disability concept notions. Experimental weight stigma reduction studies, mainly challenging personal controllability and responsibility beliefs through information about the biogenetic causes of obesity, have meta-analytically resulted in a small positive effect reducing weight stigma [32]. Building on this research, future experimental studies could investigate the effects of precise disease or disability definitions in obesity in regards to weight-related public and self-stigma outcomes, considering the cognitive-affective mechanisms involved and potential side effects including essential views of fundamental differentness with a potential stigma-inducing effect [33]. Herein, disease and disability definitions may be considered to reflect the multifactorial etiology or consequences of obesity, for example, within a biopsychosocial framework.

Regarding public health implications, the recognition of obesity as a disease has been increasingly present in medical and political discussions, for example, on the National Diabetes Strategy issued in Germany in July 2020. While it cannot be ruled out that public views of obesity have changed since 2016 when this study's data were assessed, for the discussions about obesity as a disease or disability, our results suggest a careful use of these terms, warranting precise definitions. The disability concept in particular carries notions of mental or intellectual disability that are rarely endorsed, but are publicly devalued and co-occur with greater weight stigma. If the disability concept is used, the specific impairments (e.g., reduced mobility) associated with an individual's severe obesity may need to be explained in detail, without labeling obesity as impairment per se.

Keeping the cross-sectional nature of our results in mind, if the disease concept is aimed to be more widely accepted [34], men, older adults, and those at lower weight may represent target groups for informational campaigns with a destigmatizing focus (Table 2). Indeed, when compared to individuals with obesity, those with lower body weight agreed less with both the disease [14] and the disability concept, suggesting a lower awareness of the significant burden that may be associated with this chronic health condition. Men may be less familiar with the health implications of obesity than women because of a lower health literacy [35]. The fact that the disease concept was less endorsed, whereas the disability concept was more endorsed, by older participants than middle-aged participants may reflect that older adults may have focused more on the disability-inherent persistent impairment because of greater familiarity with age-related limitations. The reduction of the disability stigma associated with obesity requires more research, given a lack of studies on interventions [36] and basic principles in this area.

\section{Acknowledgements}

The authors are grateful to Jamie L. Manwaring, Ph.D., for her help in editing this paper.

\section{Statement of Ethics}

All procedures involving human participants were in accordance with the ethical standards of the Institutional and/or National Research Committee, and with the 1964 Helsinki declaration and its later amendments or comparable ethical standards. All participants were informed about the study procedures in a verbal and written format and signed an informed consent prior to assessment. All procedures were approved by the Ethics Committee of the Medical Faculty of Leipzig University (no. 452-15-21122015).

\section{Conflict of Interest Statement}

The authors have no conflicts of interest to disclose.

\section{Funding Sources}

This research was supported by internal funds of the Behavioral Medicine Research Unit, Integrated Research and Treatment Center AdiposityDiseases, Department of Psychosomatic Medicine and Psychotherapy, University of Leipzig Medical Center, Leipzig, Germany. AH was supported by the German Federal Ministry of Education and Research (grant no. 01EO1501). We acknowledge support from the German Research Foundation (DFG) and Leipzig University within the program of open access publishing. Funding bodies had no role in the design of the study, collection and analysis of data, and decision to publish.

\section{Author Contributions}

A.H. conceptualized and designed the study, analyzed the data, and drafted the manuscript. A.H., M.Z., and E.B. were responsible for data acquisition. All the authors contributed to the interpretation of the data, revised the manuscript critically for important intellectual content, approved the final manuscript, and agreed to be accountable for all aspects of the work in ensuring that questions related to the accuracy or integrity are appropriately investigated and resolved. 


\section{References}

1 World Health Organization. Overweight and obesity; 2020 [cited 2020 Oct 15]. Available from: https://www.who.int/en/news-room/ fact-sheets/detail/obesity-and-overweight.

2 Pearl RL, Puhl RM. Weight bias internalization and health: a systematic review. Obes Rev. 2018;19:1141-63.

3 Kyle TK, Dhurandhar EJ, Allison DB. Regarding obesity as a disease: evolving policies and their implications. Endocrinol Metab Clin North Am. 2016;45:511-20.

4 American Medical Association (AMA). Report of the Council on science and public health report 3-A-13. Is obesity a disease? AMA House of Delegates Annual Meeting. Chicago, IL; 2013 Jun [cited 2021 Mar 30]. Available from: https://www.ama-assn.org/ sites/ama-assn.org/files/corp/media-browser/public/about-ama/councils/Council\%20 Reports/council-on-science-public-health/ a13csaph3.pdf.

5 Bray GA, Kim KK, Wilding JPH; World Obesity Federation. Obesity: a chronic relapsing progressive disease process. A position statement of the World Obesity Federation. Obes Rev. 2017;18:715-23.

6 Sharma AM, Goodwin DL, Causgrove Dunn J. Conceptualizing obesity as a chronic disease: an interview with Dr. Arya Sharma. Adapt Phys Activ Q. 2018;35:285-92.

7 Vallgårda S, Nielsen MEJ, Hansen AKK, Cathaoir KÓ, Hartlev M, Holm L, et al. Should Europe follow the US and declare obesity a disease? A discussion of the so-called utilitarian argument. Eur J Clin Nutr. 2017;71:1263-

8 Scully JL. What is a disease? EMBO Rep. 2004; 5(7):650-3.

9 De Lorenzo A, Gratteri S, Gualtieri P, Cammarano A, Bertucci P, Di Renzo L. Why primary obesity is a disease? J Transl Med. 2019; 17:169.

10 Müller MJ, Geisler C. Defining obesity as a disease. Eur J Clin Nutr. 2017;71:1256-8.

11 Slater SB, Vukmanovic C, Macukanovic P, Prvulovic T, Cutler JL. The definition and measurement of disability. Soc Sci Med. 1974; 8:305-8.

12 World Health Organization. International classification of impairments, disabilities, and handicaps: a manual of classification relating to the consequences of disease, published in accordance with resolution WHA29.35 of the 29th World Health Assembly, May 1976. Geneva: World Health Organization; 1980 [cited 2021 Mar 30]. Available from: https://apps. who.int/iris/handle/10665/41003.

13 Hilbert A, Rief W, Braehler E. Stigmatizing attitudes toward obesity in a representative population-based sample. Obesity. 2008; 16 : 1529-34.

14 Puhl RM, Liu S. A national survey of public views about the classification of obesity as a disease. Obesity. 2015;23:1288-95.

15 Kaur Y, de Souza RJ, Gibson WT, Meyre D. A systematic review of genetic syndromes with obesity. Obes Rev. 2017;18:603-34.

16 Volkow ND, O'Brien CP. Issues for DSM-V: should obesity be included as a brain disorder? Am J Psychiatry. 2007;164:708-10.

17 Weiner B. An attributional theory of motivation and emotion. New York: Springer; 1986.

18 Luck-Sikorski C, Schomerus G, Jochum T, Riedel-Heller SG. Layered stigma? Co-occurring depression and obesity in the public eye. J Psychosom Res. 2018;106:29-33.

19 Chang VW, Alley DE, Dowd JB. Trends in the relationship between obesity and disability, 1988-2012. Am J Epidemiol. 2017;186:68895.

20 Flint SW, Snook J. Disability, discrimination and obesity: the big questions? Curr Obes Rep. 2015;4:504-9.

21 Puhl RM, Latner JD, O’Brien KS, Luedicke J, Danielsdottir S, Salas XR. Potential policies and laws to prohibit weight discrimination: public views from 4 countries. Milbank Q. 2015;93:691-731.

22 Hilbert A, Hübner C, Schmutzer G, Danielsdottir S, Brähler E, Puhl R. Public support for weight-related antidiscrimination laws and policies. Obes Facts. 2017;10:101-11.

23 Luck-Sikorski C, Riedel-Heller SG. Obesity as a disability: a representative survey of individuals with obesity from Germany. Disabil Health J. 2017;10:152-6.

24 Ditchman N, Werner S, Kosyluk K, Jones N, Elg B, Corrigan PW. Stigma and intellectual disability: potential application of mental illness research. Rehabil Psychol. 2013;58:206-16.

25 Lewis RJ, Cash TF, Jacobi L, Bubb-Lewis C. Prejudice toward fat people: the development and validation of the Antifat Attitudes Test. Obes Res. 1997;5:297-307.

26 O'Brien KS, Puhl RM, Latner JD, Lynott D, Reid JD, Vakhitova Z, et al. The effect of a food addiction explanation model for weight control and obesity on weight stigma. Nutrients. 2020;12:294.

27 Federal Statistical Office. Bevölkerung: Deutschland, Stichtag, Altersjahre, Nationalität, Geschlecht, Familienstand [Population: Germany, date, age, nationality, sex, marital status]; 2016 [cited 2021 Jan 29]. Available from: https://www-genesis.destatis.de/.

28 German National Cohort Consortium. The German National Cohort: aims, study design and organization. Eur J Epidemiol. 2014;29: 371-82.

29 Connor Gorber S, Tremblay M, Moher D, Gorber B. A comparison of direct vs. self-report measures for assessing height, weight and body mass index: a systematic review. Obes Rev. 2007;8:307-26.

30 Mensink GB, Schienkiewitz A, Haftenberger M, Lampert T, Ziese T, Scheidt-Nave C. Übergewicht und Adipositas in Deutschland: Ergebnisse der Studie zur Gesundheit Erwachsener in Deutschland (DEGS1) [Overweight and obesity in Germany: results of the German Health Interview and Examination Survey for Adults (DEGS1)]. Bundesgesundheitsblatt Gesundheitsforschung Gesundheitsschutz. 2013;56:786-94.

31 Emmer C, Bosnjak M, Mata J. The association between weight stigma and mental health: a meta-analysis. Obes Rev. 2020;21:e12935.

32 Lee M, Ata RN, Brannick MT. Malleability of weight-biased attitudes and beliefs: a metaanalysis of weight bias reduction interventions. Body Image. 2014;11:251-9.

33 Hilbert A. Weight stigma reduction and genetic determinism. PLoS One. 2016;11(9): e0162993.

34 Rubino F, Puhl RM, Cummings DE, Eckel $\mathrm{RH}$, Ryan DH, Mechanick JI, et al. Joint international consensus statement for ending stigma of obesity. Nat Med. 2020;26:485-97.

35 Oliffe JL, Rossnagel E, Kelly MT, Bottorff JL, Seaton C, Darroch F. Men's health literacy: a review and recommendations. Health Promot Int. 2020;35(5):1037-51.

36 Smythe T, Adelson JD, Polack S. Systematic review of interventions for reducing stigma experienced by children with disabilities and their families in low- and middle-income countries: state of the evidence. Trop Med Int Health. 2020;25:508-24. 